\title{
Antibody preparation and identification of the Cashmere goat c-kit protein in the testes
}

\author{
S.C.L. Wu*, F.H. Luo*, Q.F. Kong and Y.J. Wu
}

Key Laboratory of China Education Ministry for the Research of Mammal Reproductive Biology and Biotechnology, Inner Mongolia University, Hohhot, China

*These authors contributed equally to this study.

Corresponding author: Y.J. Wu

E-mail: yingji_wu@yahoo.com

Genet. Mol. Res. 13 (3): 4856-4866 (2014)

Received March 20, 2013

Accepted October 5, 2013

Published July 2, 2014

DOI http://dx.doi.org/10.4238/2014.July.2.13

\begin{abstract}
The c-kit protein plays a major role in the regulation of germ cell development. Its expression and distribution in rodent testes have been widely reported. However, research regarding c-kit expression in domestic animals is scarce, and the expression pattern and distribution of c-kit in germ cells have not been clearly defined. In this study, a specific antigenic region for goat c-kit was designed, and a c-kit polyclonal antibody was prepared. This antibody was then applied in a study evaluating c-kit expression in Cashmere goat tissues. A Western blot analysis showed that three forms of c-kit were expressed in goat testes: precursor, mature, and soluble c-kit. Fluorescent immunohistochemical analyses showed that c-kit was primarily expressed in the spermatogonia and spermatocytes of goat testes. These results not only clarify the expression and localization of c-kit in the
\end{abstract}


goat testis, but also accelerate further research regarding the function of c-kit in goat spermatogenesis.

Key words: c-kit; c-kit expression; Polyclonal antibody; Testis; Cashmere goat

\section{INTRODUCTION}

The general functions of c-kit (kit receptor or CD117) and kit ligand (stem cell factor, SCF or KITL) were previously described in rodents (Mintz, 1957; Russell, 1979). Through an analysis of the v-kit oncogene, the c-kit gene was first localized to the White-spotting (W) locus (Chabot et al., 1988). The c-kit gene was mapped to chromosome 4 in humans and to chromosome 5 in mice (Mauduit et al., 1999). Considered to be an oncogene, the c-kit gene is encoded by 21 exons spanning over $20 \mathrm{~kb}$ in humans (Vandenbark et al., 1992), and encodes a $5.5-\mathrm{kb}$ transcript in the mouse. The c-kit precursor protein has a molecular weight of 120 $\mathrm{kDa}$, and can be post-translationally modified into the $145-160-\mathrm{kDa}$ mature transmembrane receptor protein (Yarden et al., 1987; Dym et al., 1995) that belongs to the class III receptor tyrosine kinase family. In addition to the two c-kit forms mentioned above, the c-kit protein also occurs in a truncated form (Tr-kit) and a soluble isoform (S-kit). Due to the lack of complete extracellular and transmembrane domains, Tr-kit cannot interact with SCF, but plays an important role in the acrosomal reaction at fertilization in the mouse (Sette et al., 1997). The soluble c-kit isoform is expressed on the surface of hematopoietic cells, mast cells, and endothelial cells, and it circulates freely in human plasma (Wypych et al., 1995). This isoform is the result of proteolytic cleavage at the junction of the transmembrane and extracellular domains, and shows the same affinity for SCF as the full-length protein. S-kit can block the SCF-induced stimulation of hematopoietic colony growth in vitro, which indicates that S-kit can also functionally modulate SCF bioactivity (Dahlen et al., 2001). Importantly, the c-kit protein plays a major role in the regulation of rodent germ cell development. In the embryonic stage, c-kit participates in the migration of primordial germ cells and in the survival and differentiation of gonocytes (Rossi et al., 2000). In the mouse post-pubertal stage, the expression of c-kit has been confirmed in the Leydig cells, spermatogonia, pachytene spermatocytes, and spermatids, but it has not been detected in the undifferentiated spermatogonia or in Sertoli cells (Packer et al., 1995; Sette et al., 1997; Rothschild et al., 2003).

To further study the expression pattern of c-kit in domestic animals and to accurately determine c-kit localization in goat testes, we cloned the fragment of the Cashmere goat c-kit gene and designed a specific antigen for goat c-kit. After prokaryotic expression and mouse immunization, we successfully obtained a mouse anti-goat c-kit polyclonal antibody, which was used to analyze c-kit expression in goat tissues. Consequently, we determined the expression patterns of c-kit in different goat tissues and its localization in testis cross-sections.

\section{MATERIAL AND METHODS}

\section{Animals and tissue preparation}

The testes were collected from 6- to 8-month-old Cashmere goats from the Engebei 
Stud Farm of the Yih Ju League Cashmere Sweater Factory, and were transported to the laboratory within $2 \mathrm{~h}$ for total RNA extraction, Western blotting, and immunofluorescence experiments. KunMing mice were purchased from the Laboratory Animal Research Center of Inner Mongolia University, China. All animal experiments were performed according to the Guide for Care and Usage of Laboratory Animals by the Research Center for Laboratory Animals, Inner Mongolia University.

\section{Antigen prediction}

Based on the homology of the published Shiba goat c-kit gene (GenBank accession No. D45168.1), the most probable antigenic site was predicted by the computer-assisted antigen prediction software obtained from the Harvard University website (http://immunax.dfci. harvard.edu/Tools/antigenic.html\#Software). The $\alpha, \beta$, turn, coil regions, antigenic index, and surface probability were predicted using the DNAStar software, and the antigen specificity was analyzed using the National Center for Biotechnology Information (NCBI) online BLAST program. Combining all of the above results, the region with the most probable antigenic site was selected based on the highest number of potential antigenic determinants, high antigenic index, surface probability, and high specificity.

\section{Cloning of the c-kit antigenic region}

The total RNA was extracted from 6- to 8-month-old Cashmere goat testes using the RNAsimple total RNA kit (TaKaRa, Dalian, China). The first strand of cDNA was synthesized by reverse transcription of $1 \mu \mathrm{g}$ total RNA using reverse transcriptase M-MLV (RNase $\mathrm{H}^{-}$) (TaKaRa). The polymerase chain reaction (PCR) amplification was performed with gene-specific primers designed by PrimerPremier 5 (PREMIER Biosoft International), which were complementary to the predicted antigenic region of the c-kit gene. The primer sequences used for the PCR amplification were as follows: sense primer (5'-AAC CAT ATG CTG GTT CGC TGT CCC C-3') and antisense primer (5'-TGT CTC GAG GCC TCC TTC AGT CCC T-3'), in which underlined nucleotides indicate the restriction sites for the restriction enzymes NdeI and XhoI, respectively. All PCR assays described in this study were conducted under the following conditions: an initial denaturation at $94^{\circ} \mathrm{C}$ for $4 \mathrm{~min}$, followed by 35 cycles of denaturation at $94^{\circ} \mathrm{C}$ for $40 \mathrm{~s}$, annealing at $57^{\circ} \mathrm{C}$ for $1 \mathrm{~min}$, extension at $72^{\circ} \mathrm{C}$ for $1 \mathrm{~min}$, and a final extension at $72^{\circ} \mathrm{C}$ for $10 \mathrm{~min}$ using rTaq DNA polymerase. The 789-bp PCR product was ligated into the pMD19-T vector $(\mathrm{TaKaRa})$ for the construction of the recombinant pMD19-T-gc-kit plasmid, and finally confirmed by DNA sequencing (TaKaRa).

\section{Prokaryotic expression of the antigen}

The amplified fragment was inserted into the prokaryotic expression vector pET$44 \mathrm{a}(+)$ (Novagen, USA) between the $N d e \mathrm{I}$ and $\mathrm{XhoI}$ sites to construct the pET-44a-c-kit antigen expression vector. The construction of the vector was confirmed by DNA sequencing as described above. Prokaryotic expression of the His-c-kit antigenic peptide was performed in Escherichia coli BL21 (DE3) (Novagen). For the optimization of induction conditions, the 
bacterial culture was induced with $1.0 \mathrm{mM}$ isopropyl $\beta$-D-1-thiogalactopyranoside (IPTG) for $3,4,6$, and $7 \mathrm{~h}$. After induction, the same amount of total protein from each sample was analyzed by $12 \%$ sodium dodecyl sulfate-polyacrylamide gel electrophoresis (SDS-PAGE) with a parallel analysis of the uninduced culture as a control group.

\section{Protein purification by affinity chromatography}

The recombinant His-c-kit antigenic peptide was purified using a Ni-NTA His $\bullet$ Bind $^{\circledR}$ Resin column (Novagen) based on the affinity between the His ${ }_{6}$-Tag and an immobilized metal ion (usually $\mathrm{Ni}^{2+}$ ). The detailed purification procedure was performed according to manufacturer instructions. For the optimization, the target proteins were eluted with the $1 \mathrm{X}$ Ni-NTA Elute Buffer, containing $100 \mathrm{mM}$ to $1 \mathrm{M}$ concentrations of imidazole, and the presence of recombinant proteins in the eluted fractions was confirmed by Western blot analysis.

\section{Western blotting}

The purified proteins were separated by $12 \%$ SDS-PAGE, and were then electrotransferred to a $0.45-\mu \mathrm{m}$ Immobilon-P polyvinylidene fluoride (PVDF) membrane (Millipore) using a Bio-Rad apparatus at $100 \mathrm{~mA}$ for $1 \mathrm{~h}$. The membranes were initially blocked with $5 \%$ skim milk in $1 \mathrm{X}$ Tris-buffered saline with $0.1 \%$ Tween 20 (TBST) at room temperature for $2 \mathrm{~h}$ with slow agitation, and were then incubated overnight at $4{ }^{\circ} \mathrm{C}$ with mouse anti-6X His-Tag monoclonal antibody (Tiangen Biotech, Beijing) at 1:250 dilution in blocking buffer. Blots were washed with 1X TBST three times and incubated for $2 \mathrm{~h}$ at room temperature with the alkaline phosphatase (AP)-conjugated goat anti-mouse secondary antibody (Tiangen Biotech) at a 1:3000 dilution in 1X TBST. After washing with 1X TBST three times, the antigenic band was visualized using the NBT/BCIP substrate solution (Tiangen Biotech). The purified antigen was mixed with glycerol to a final concentration of $20 \%$, and then stored at $-80^{\circ} \mathrm{C}$ for further analysis.

\section{Polyclonal antibody preparation}

Six- to eight-week-old female KunMing mice were immunized with $30 \mu \mathrm{g}$ purified antigen in Freund's adjuvant (Bio Basic Canada Inc.) by hypodermic injection. Every mouse was immunized a total of five times at injection intervals of 12 days. One week after the final injection, $1 \times 10^{6} \mathrm{~S} 180$ cells suspended in $1 \mathrm{~mL}$ medium were injected intraperitoneally into each mouse to induce the secretion of ascetic fluid. After injection for approximately 2 weeks, the ascetic fluid was harvested. Then, the supernatant of the ascetic fluid was collected by centrifugation at 13,000 rpm for $10 \mathrm{~min}$. Each fraction of antibody was mixed with an equal volume of storage buffer [2X phosphate-buffered saline (PBS) with $2 \%$ bovine serum albumin, $40 \%$ glycerol, and $2 \% \mathrm{NaN}_{3}$ ], and stored in aliquots at $-20^{\circ} \mathrm{C}$.

\section{Localization of the goat c-kit protein}

To characterize c-kit expression in different tissues and its distribution in goat testes, we performed Western blotting and immunofluorescence staining. The total proteins 
were isolated from the goat testis, kidney, liver, and lung, using previously described methods (Xu et al., 1998). Forty microgram aliquots of protein were separated by $8 \%$ SDS-PAGE and electro-transferred to PVDF membranes. A Western blot analysis was performed as described above using the anti-goat c-kit polyclonal antibody as the primary antibody at a 1:100 dilution and the AP-conjugated goat anti-mouse IgG secondary antibody (Beyotime Biotechnology, China) at a 1:3000 dilution. After washing with $1 \mathrm{X}$ TBST three times, the antigenic band was visualized using the NBT/BCIP substrate solution (Tiangen Biotech).

To determine the distribution of the c-kit protein in goat testes, immunofluorescence staining was performed using frozen sections of goat testis tissue. The preparation of the frozen goat testis sections and the immunofluorescence staining were performed as previously described (Zhang et al., 2011). Briefly, the samples were fixed with an aldehyde-fixing agent at $4^{\circ} \mathrm{C}$ for an optimized period of time. After fixation, the samples were washed with 1X Dulbecco's PBS three times and then blocked with 5\% (v/v) skim milk for $30 \mathrm{~min}$ at room temperature, followed by incubation with the anti-goat c-kit polyclonal antibody in the blocking buffer at $4^{\circ} \mathrm{C}$ overnight. The negative control was incubated in the blocking buffer without the primary antibody. The slides were rinsed three times and then incubated with $\mathrm{Cy} 3$-conjugated goat anti-mouse $\operatorname{IgG}(\mathrm{H}+\mathrm{L})$ secondary antibodies (1:200, Beyotime Biotechnology) for 30 $\mathrm{min}$ at room temperature. Subsequently, the slides were washed again and counterstained with Hochest33258 (Sigma-Aldrich, Shanghai, China) before mounting and observation under an inverted Nikon microscope.

\section{RESULTS}

\section{Antigen prediction and cloning}

The results of online antigen prediction determined that the region containing eight antigenic determinants could be selected as a potential antigen (Table 1). The DNAStar software analysis (Figure 1) showed that the selected region fit the antigenic characteristics, the antigenic index was higher than 0 (mean 0.71 ), and the surface probability was higher than 1 (mean 1.26). The specificity of the antigen was analyzed using the NCBI DELTA-BLAST software, which showed that all of the sequences with a maximum identity greater than $90 \%$ were c-kit genes. A conserved domain analysis showed that the antigenic region had the lowest E-value (5.66e-38) and the highest similarity with the c-kit protein. On the basis of complete homology with the Shiba goat c-kit structure (Tanaka et al., 1997), we putatively localized our antigen to the extracellular domain of the intact c-kit receptor.

\begin{tabular}{|c|c|c|c|}
\hline No. & Start position & Sequence & End position \\
\hline 1 & 24 & LPKDLTFVADP & 34 \\
\hline 2 & 44 & KREYHRLCLHCSA & 56 \\
\hline 3 & 66 & KKFTLKVRAAIKAVPVVSVSKTSYLL & 91 \\
\hline 4 & 96 & EFAVTCLIKDVSSSVDS & 112 \\
\hline 5 & 134 & GDFSYLRQ & 141 \\
\hline 6 & 172 & TTLEVVDK & 179 \\
\hline 7 & 199 & NVDLVVEYEA & 208 \\
\hline 8 & 242 & YVNELHLT & 249 \\
\hline
\end{tabular}




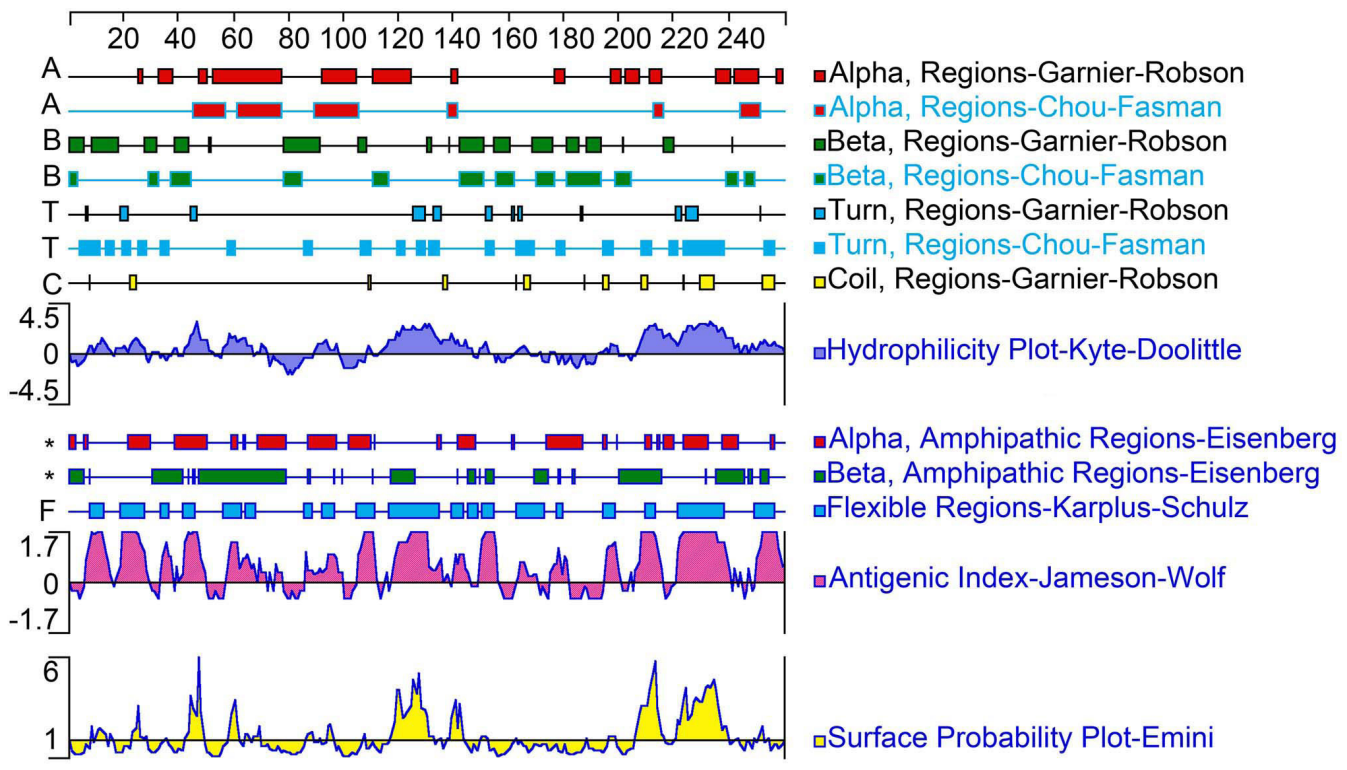

Figure 1. Computer-assisted analysis of the c-kit fragment by the DNA star software. The picture demonstrated each characteristic of goat partial c-kit with corresponding calculating method. Hydrophilicity plot, antigenic index, and surface probability were three main indexes of antigen prediction, which were judged by higher than each corresponding baseline ( 0 or 1$)$ as the predicting guide.

Subsequently, the selected 789-bp goat c-kit gene fragment was successfully amplified (Figure 2A) to construct a cloning vector. DNA sequencing results from the recombinant pMD19-T-gc-kit plasmid indicated that the amplified fragment was cloned correctly.

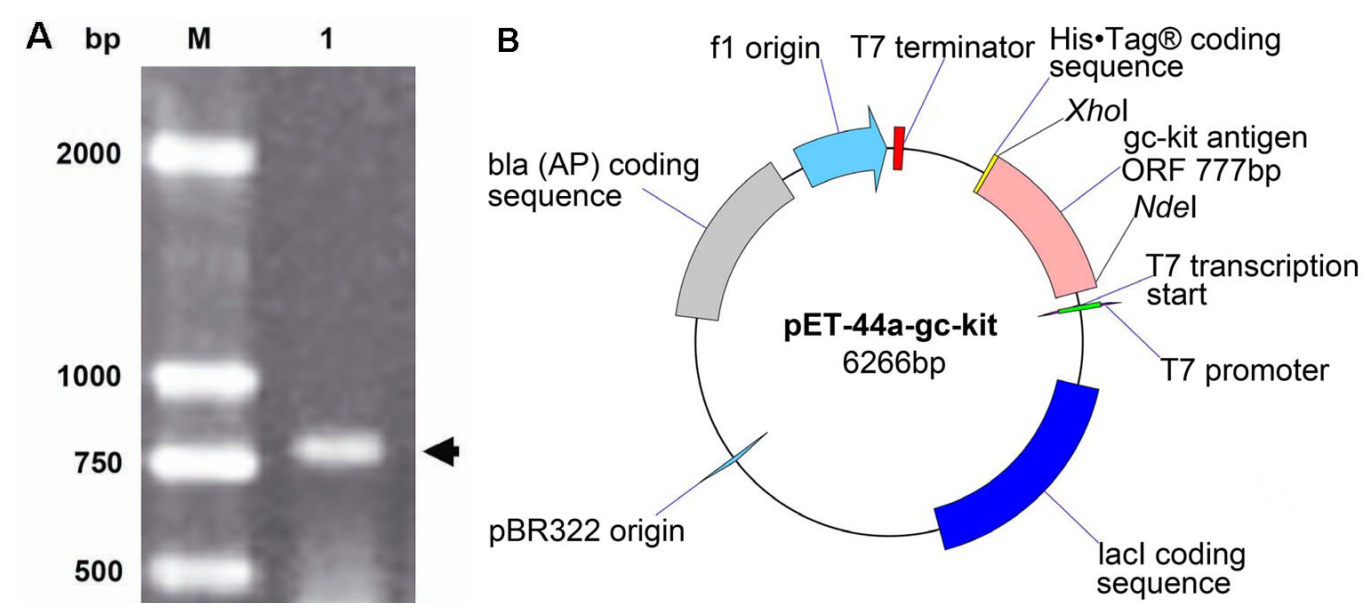

Figure 2. Amplification of target gene and construction of expression vector. A. Amplification of partial Cashmere goat c-kit. Lane $M=$ DNA molecular weight marker; lane $1=789$-bp PCR product of Cashmere goat c-kit antigenic region. B. Schematic diagram of the pET-44a-c-kit antigen expression vector. T7 promoter drives expression of c-kit antigen and His-Tag fusion peptide in the host Escherichia coli BL21 cells. 


\section{Antigen expression and purification}

The pET-44a-c-kit antigen expression vector was constructed (Figure 2B) for prokaryotic expression. To optimize the induction conditions and purification procedure, a series of preliminary experiments were performed. The recombinant bacteria were induced with or without $1 \mathrm{mM}$ IPTG at $37^{\circ} \mathrm{C}$ for $3,4,6$, and $7 \mathrm{~h}$, as shown in Figure $3 \mathrm{~A}$. The expression of the recombinant protein increased over time and reached its highest level when the induction time was extended to $6 \mathrm{~h}$. The amount of target protein started to decrease at $7 \mathrm{~h}$ after induction. Thus, the optimized induction conditions for the goat c-kit antigen expression in E. coli BL21 consisted of culturing the bacteria with $1 \mathrm{mM} \mathrm{IPTG}$ at $37^{\circ} \mathrm{C}$ for $6 \mathrm{~h}$. After growing an optimal intermediate culture, the recombinant antigen protein was purified using a Ni-NTA His•Bind ${ }^{\circledR}$ Resin column. By treatment with different concentrations of imidazole, the optimal concentration of imidazole in the elution buffer was determined to be $250 \mathrm{mM}$ (Figure 3B). A Western blot analysis was used to verify the expression, and the $30-\mathrm{kDa}$ target bands were predominantly observed in the $250 \mathrm{mM}$ elution lanes. Based on optical density calculation, approximately $75 \%$ of the purified target protein was recovered from the total elution by $250 \mathrm{mM}$ imidazole.

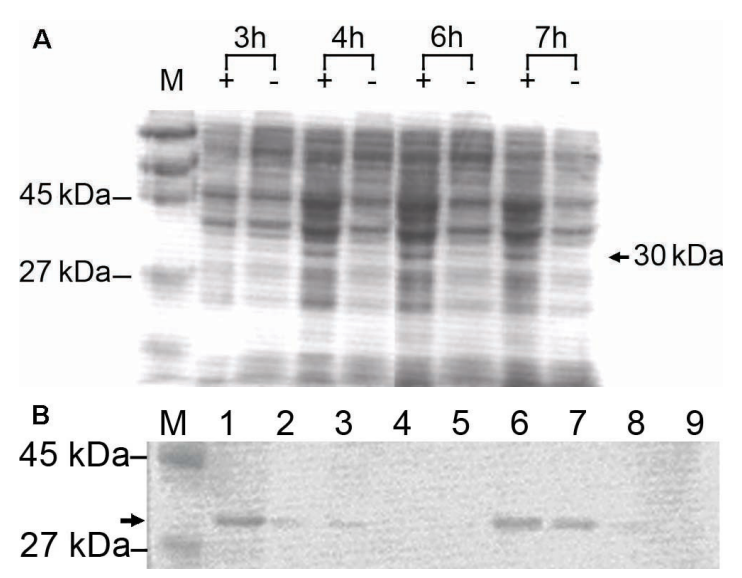

Figure 3. IPTG induction and purification of recombinant protein. A. SDS-PAGE analysis of the recombinant His-c-kit antigenic protein expression level inducted by IPTG at different time points. The recombinant bacterium was induced without (-) or with (+) $1 \mathrm{mM} \mathrm{IPTG}$ at $37^{\circ} \mathrm{C}$ for $3,4,6$, and $7 \mathrm{~h}$. Lane $M=$ pre-stained protein marker III (Tiangen Biotech, MP204). The 30-kDa band indicates the recombinant His-c-kit antigenic protein. B. Purification of the recombinant His-c-kit antigenic protein. Recombinant His-c-kit antigenic protein was expressed in Escherichia coli, lysed, loaded onto the column, and eluted by a stepwise imidazole gradient. Lane $M=$ prestained protein marker III (Tiangen Biotech, MP204). Lane $1=$ cleared lysate. Lanes 2 and $3=$ Ni-NTA final wash. Lanes 4 and $5=$ fraction eluted with $100 \mathrm{mM}$ imidazole. Lanes 6 and $7=$ fraction eluted with $250 \mathrm{mM}$ imidazole. Lane $8=$ fraction eluted with $500 \mathrm{mM}$ imidazole. Lane $9=$ fraction eluted with $1 \mathrm{M}$ imidazole. Arrow indicates the recombinant His-c-kit protein.

\section{Western blot analysis of goat c-kit}

The expression pattern of the c-kit receptor in normal goat testis, kidney, liver, and lungs was determined by Western blot analysis using the mouse anti-goat c-kit polyclonal antibody described above. As shown in Figure 4, the strong immunopositive bands at approxi- 
mately 170,120 , and $100 \mathrm{kDa}$ were specifically detected in the testis tissue. The $120-\mathrm{kDa}$ band was determined to be the c-kit precursor protein (Rubin et al., 2001), and the 170-kDa band was most likely the tyrosine-phosphorylated form of the protein (Kindler et al., 2004). The 100-kDa band was probably the soluble form (Tanikawa et al., 1998; Mukhopadhyay et al., 2011) of c-kit, and this finding suggested that the soluble form of c-kit might also function in the goat testis.

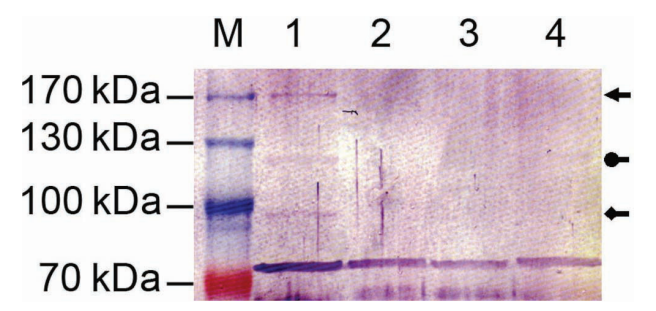

Figure 4. Western blot analysis of c-kit expression in different goat tissues. Lane $M=$ molecular mass markers. Lane 1 = cell lysate of testis tissue. Lane $2=$ cell lysate of kidney tissue. Lane $3=$ cell lysate of liver tissue. Lane $4=$ cell lysate of lung tissue. Normal arrow = mature c-kit (or tyrosine-phosphorylated form of c-kit). Round-head arrow $=$ precursor $\mathrm{c}-\mathrm{kit}$. Diamond-head arrow $=$ soluble c-kit $(\mathrm{S}-\mathrm{kit})$.

\section{Immunofluorescence staining of frozen tissue sections}

We performed immunofluorescence staining on frozen mature goat testis sections to determine the specific localization of c-kit expression in the testis. The results showed that goat c-kit localized near the basement membrane cells and had the appearance of single, paired, and aligned, whereas there was no immunoreactivity in the control group (Figure 5). Morphologically, we identified some spermatogonia and spermatocytes with positive signals, whereas the spermatids did not show any reactivity.

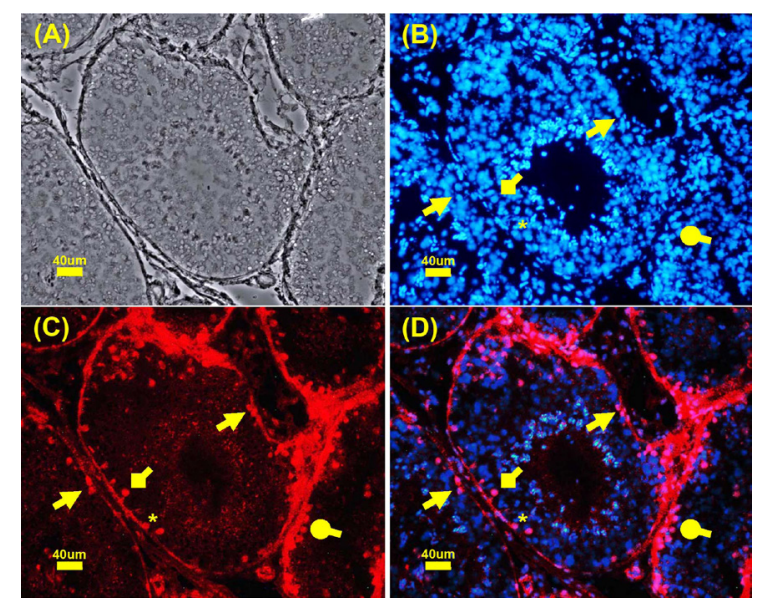

Figure 5. Localization of the c-kit protein in the goat testes. A. Corresponding bright-field image of goat testis slide. B. Hoechst 33342 counter staining of nuclei. C. c-kit antibody staining. D. Merge of Hoechst 33342 and c-kit antibody staining. Because slide is a plane structure, not all of the spermatogonia and spermatocytes (diamond-head arrow) appeared in a long-chain form. In this slide, the c-kit-positive spermatogonia scattered in a single (asterisk), paired (normal arrow) or aligned (round-head arrow) performance. 


\section{DISCUSSION}

In the adult mammal testis, the c-kit/SCF system plays an important role in the regulation of germ cell proliferation, differentiation, and fertilization (Schrans-Stassen et al., 1999). Recently, the truncated form of c-kit was reported to function in sperm-oocyte interactions in the mouse. However, the expression of c-kit in undifferentiated spermatogonia and spermatids remains debatable. Many studies have confirmed that c-kit is expressed in partially undifferentiated spermatogonia (Morimoto et al., 2009; Suzuki et al., 2009; Nakagawa et al., 2010), and that c-kit-positive spermatogonia could repopulate in recipient testes after transplantation (Barroca et al., 2009). Spermatogonial stem cells (SSCs) can change their phenotype according to different niches, and the c-kit-positive spermatogonia were speculated to be an intermediate state of SSCs (Morimoto et al., 2009). Thus, these previous studies provided detailed insight into the biological functions of c-kit in adult rodent testes. However, the expression of c-kit and its biological functions in domestic animals remain largely unknown. Due to the differences in the protocols and evolutionary disparity, knowledge of spermatogenesis in livestock lags behind that of rodents. Research on domestic animal spermatogenesis could be accelerated by the development of validated reagents (e.g., antibodies for SSC markers) and experimental tools (e.g., xenotransplantation and xenografting) (Hermann et al., 2010). In the present study, we established a simple and effective method to develop specific antibodies for the goat c-kit protein and provided a basis for future studies regarding the biological functions of c-kit in goats.

The antibody generated in this study showed high specificity for the goat c-kit protein. A partial region of c-kit containing eight antigenic determinants was selected as the antigen. Generally, using large regions of the target protein as an antigen is a more successful approach for antibody production because the large region is able to generate a folded structure and a diversity of epitopes, which increases the chance that an antibody might work in an immunoassay.

This study describes the first detection of the c-kit expression pattern in goat tissues. The Western blot results confirmed the existence of a precursor, mature, and soluble form of c-kit in goat testes, although the previously reported $145-\mathrm{kDa}$ mature and $30-\mathrm{kDa}$ truncated c-kit that were detected in rodents (Majumder et al., 1988; Sette et al., 1997) were not detected in goat tissues. Post-translational glycosylation and phosphorylation of the c-kit precursor are the primary explanations for differences in molecular weight. The c-kit protein with a large molecular weight $(\sim 170 \mathrm{kDa})$ observed in our study was similar to the $160-\mathrm{kDa}$ activated mouse c-kit described in other reports (Dym et al., 1995; Kindler et al., 2004; Cristofanilli et al., 2008; Mukhopadhyay et al., 2011). It is possible that the mature c-kit protein is approximately $170 \mathrm{kDa}$ after activation in the goat. Furthermore, the human $95-\mathrm{kDa}$ soluble c-kit protein (Wypych et al., 1995) correlated with the $\sim 100-\mathrm{kDa}$ band observed in the present study. However, these target bands were not observed in the goat kidney, liver, or lungs. Because the expression of c-kit is limited to specific normal human tissue cell types, including mast cells, germ cells, melanocytes, breast epithelium, and interstitial cells of Cajal (Tsuura et al., 1994; Huizinga et al., 1995; Hornick and Fletcher, 2002), there are no reports regarding tissue-specific c-kit expression in goats. In conclusion, we described the first analysis of the c-kit expression pattern in several goat tissues and found that c-kit is not detected in the normal goat kidney, liver, or lungs. However, it is expressed in the testis as both a mature and soluble functional protein.

To further study the expression of c-kit in the goat germ line, we applied the c-kit anti- 
body to immunofluorescence staining of frozen goat tissue sections. The results demonstrated the localization of c-kit to the membranes of spermatogonia and spermatocytes. We found that the c-kit-positive spermatogonia distributed on the basement membrane of each seminiferous tubule, and few c-kit-positive spermatocytes with relatively large round nuclei were found at the midlevel of each tubular epithelium. The truncated c-kit protein was not detected on the spermatids using our antibody, which was consistent with the Western blot results. The primary reason for this observation is that the antigen was designed for the outer membrane region of c-kit, and the truncated intercellular portion of the c-kit protein could not be detected. Overall, the immunofluorescence-staining results were consistent with the results observed in rodents (Prabhu et al., 2006).

In summary, this is the first report regarding the preparation of an antibody based on the Cashmere goat c-kit sequence, and the first analysis of c-kit expression in Cashmere goat tissues. We established a simple, low-cost, functional, and reproducible antibody preparation protocol. Furthermore, we demonstrated the existence of precursor, mature, and soluble forms of c-kit in the goat testis, which were not detectable in the other three tissues tested in this study. Finally, we found that c-kit expression localized to the spermatogonia and spermatocytes in the goat testis sections. These results not only provide a reference for further research on domestic animals, but also facilitate the study of c-kit function in goat spermatogenesis.

\section{ACKNOWLEDGMENTS}

We thank Professor Rex A. Hess (University of Illinois) for kindly providing the STAGE software, which was helpful for the morphological identification of male germ cells. We would like to thank Ms. Zhaoying Wu for her help with manuscript preparation. Research supported by the Ph.D. Programs Foundation of the Ministry of Education of China (\#20101501110001).

\section{REFERENCES}

Barroca V, Lassalle B, Coureuil M, Louis JP, et al. (2009). Mouse differentiating spermatogonia can generate germinal stem cells in vivo. Nat. Cell Biol. 11: 190-196.

Chabot B, Stephenson DA, Chapman VM, Besmer P, et al. (1988). The proto-oncogene c-kit encoding a transmembrane tyrosine kinase receptor maps to the mouse W locus. Nature 335: 88-89.

Cristofanilli M, Morandi P, Krishnamurthy S, Reuben JM, et al. (2008). Imatinib mesylate (Gleevec) in advanced breast cancer-expressing C-Kit or PDGFR-beta: clinical activity and biological correlations. Ann. Oncol. 19: 1713-1719.

Dahlen DD, Lin NL, Liu YC and Broudy VC (2001). Soluble Kit receptor blocks stem cell factor bioactivity in vitro. Leuk. Res. 25: 413-421.

Dym M, Jia MC, Dirami G, Price JM, et al. (1995). Expression of c-kit receptor and its autophosphorylation in immature rat type A spermatogonia. Biol. Reprod. 52: 8-19.

Hermann BP, Sukhwani M, Hansel MC and Orwig KE (2010). Spermatogonial stem cells in higher primates: are there differences from those in rodents? Reproduction 139: 479-493.

Hornick JL and Fletcher CD (2002). Immunohistochemical staining for KIT (CD117) in soft tissue sarcomas is very limited in distribution. Am. J. Clin. Pathol. 117: 188-193.

Huizinga JD, Thuneberg L, Kluppel M, Malysz J, et al. (1995). W/kit gene required for interstitial cells of Cajal and for intestinal pacemaker activity. Nature 373: 347-349.

Kindler T, Breitenbuecher F, Marx A, Beck J, et al. (2004). Efficacy and safety of imatinib in adult patients with c-kitpositive acute myeloid leukemia. Blood 103: 3644-3654.

Majumder S, Brown K, Qiu FH and Besmer P (1988). c-kit protein, a transmembrane kinase: identification in tissues and characterization. Mol. Cell. Biol. 8: 4896-4903.

Mauduit C, Hamamah S and Benahmed M (1999). Stem cell factor/c-kit system in spermatogenesis. Hum. Reprod. Update

Genetics and Molecular Research 13 (3): 4856-4866 (2014)

CFUNPEC-RP www.funpecrp.com.br 
5: 535-545.

Mintz B (1957). Embryological development of primordial germ-cells in the mouse: influence of a new mutation, Wj. $J$. Embryol. Exp. Morphol. 5: 396-403.

Morimoto H, Kanatsu-Shinohara M, Takashima S, Chuma S, et al. (2009). Phenotypic plasticity of mouse spermatogonial stem cells. PLoS One 4: e7909.

Mukhopadhyay A, Do DV, Ong CT, Khoo YT, et al. (2011). The role of stem cell factor and c-KIT in keloid pathogenesis: do tyrosine kinase inhibitors have a potential therapeutic role? Br. J. Dermatol. 164: 372-386.

Nakagawa T, Sharma M, Nabeshima Y, Braun RE, et al. (2010). Functional hierarchy and reversibility within the murine spermatogenic stem cell compartment. Science 328: 62-67.

Packer AI, Besmer P and Bachvarova RF (1995). Kit ligand mediates survival of type A spermatogonia and dividing spermatocytes in postnatal mouse testes. Mol. Reprod. Dev. 42: 303-310.

Prabhu SM, Meistrich ML, McLaughlin EA, Roman SD, et al. (2006). Expression of c-Kit receptor mRNA and protein in the developing, adult and irradiated rodent testis. Reproduction 131: 489-499.

Rossi P, Sette C, Dolci S and Geremia R (2000). Role of c-kit in mammalian spermatogenesis. J. Endocrinol. Invest. 23: 609-615.

Rothschild G, Sottas CM, Kissel H, Agosti V, et al. (2003). A role for kit receptor signaling in Leydig cell steroidogenesis. Biol. Reprod. 69: 925-932.

Rubin BP, Singer S, Tsao C, Duensing A, et al. (2001). KIT activation is a ubiquitous feature of gastrointestinal stromal tumors. Cancer Res. 61: 8118-8121.

Russell ES (1979). Hereditary anemias of the mouse: a review for geneticists. Adv. Genet. 20: 357-459.

Schrans-Stassen BH, van de Kant HJ, de Rooij DG and van Pelt AM (1999). Differential expression of c-kit in mouse undifferentiated and differentiating type A spermatogonia. Endocrinology 140: 5894-5900.

Sette C, Bevilacqua A, Bianchini A, Mangia F, et al. (1997). Parthenogenetic activation of mouse eggs by microinjection of a truncated c-kit tyrosine kinase present in spermatozoa. Development 124: 2267-2274.

Suzuki H, Sada A, Yoshida S and Saga Y (2009). The heterogeneity of spermatogonia is revealed by their topology and expression of marker proteins including the germ cell-specific proteins Nanos2 and Nanos3. Dev. Biol. 336: 222-231.

Tanaka S, Yanagisawa N, Tojo H, Kim YJ, et al. (1997). Molecular cloning of cDNA encoding the c-kit receptor of Shiba goats and a novel alanine insertion specific to goats and sheep in the kinase insert region. Biochim. Biophys. Acta 1352: 151-155.

Tanikawa M, Harada T, Mitsunari M, Onohara Y, et al. (1998). Expression of c-kit messenger ribonucleic acid in human oocyte and presence of soluble c-kit in follicular fluid. J. Clin. Endocrinol. Metab. 83: 1239-1242.

Tsuura Y, Hiraki H, Watanabe K, Igarashi S, et al. (1994). Preferential localization of c-kit product in tissue mast cells, basal cells of skin, epithelial cells of breast, small cell lung carcinoma and seminoma/dysgerminoma in human: immunohistochemical study on formalin-fixed, paraffin-embedded tissues. Virchows Arch. 424: 135-141.

Vandenbark GR, de Castro CM, Taylor H, Dew-Knight S, et al. (1992). Cloning and structural analysis of the human c-kit gene. Oncogene 7: 1259-1266.

Wypych J, Bennett LG, Schwartz MG, Clogston CL, et al. (1995). Soluble kit receptor in human serum. Blood 85: 66-73.

Xu J, Fan G, Chen S, Wu Y, et al. (1998). Methylprednisolone inhibition of TNF-alpha expression and NF-kB activation after spinal cord injury in rats. Brain Res. Mol. Brain Res. 59: 135-142.

Yarden Y, Kuang WJ, Yang-Feng T, Coussens L, et al. (1987). Human proto-oncogene c-kit: a new cell surface receptor tyrosine kinase for an unidentified ligand. EMBO J. 6: 3341-3351.

Zhang Y, Su H, Luo F, Wu S, et al. (2011). E-cadherin can be expressed by a small population of rat undifferentiated spermatogonia in vivo and in vitro. In Vitro Cell Dev. Biol. Anim. 47: 593-600. 